\title{
Iron metabolism and oxidative profile of dogs naturally infected by Ehrlichia canis: Acute and subclinical disease
}

\author{
Nathieli B. Bottari ${ }^{\text {a }}$, Leandro Z. Crivellenti ${ }^{\text {b, c, }}{ }^{* *}$, Sofia Borin-Crivellenti ${ }^{\text {b }}$, \\ Jéssica R. Oliveira ${ }^{\mathrm{b}}$, Stefanie B. Coelho ${ }^{\mathrm{b}}$, Catarina M. Contin ${ }^{\mathrm{b}}$, Etiane Tatsch ${ }^{\mathrm{d}}$, \\ Rafael N. Moresco ${ }^{d}$, Aureo E. Santana ${ }^{\text {b }}$, Alexandre A. Tonin ${ }^{\text {, }}$, Mirela Tinucci-Costa ${ }^{\text {, }}$, \\ Aleksandro S. Da Silva f, * \\ a Department of Microbiology and Parasitology, Santa Maria Federal University (UFSM), Brazil \\ ${ }^{\mathrm{b}}$ Department of Veterinary Clinic and Surgery, São Paulo State University (UNESP), Jaboticabal, Brazil \\ ${ }^{\mathrm{c}}$ Department of Veterinary Clinic and Surgery, Franca University (UNIFRAN), Franca, Brazil \\ d Department of Clinical and Toxicological Analysis, Santa Maria Federal University (UFSM), Santa Maria, RS, Brazil \\ e Department of Veterinary Medicine, Santa Catarina West University (UNOESC), Xanxerê, SC, Brazil \\ ${ }^{\mathrm{f}}$ Department of Animal Science, Santa Catarina State University (UDESC), Chapecó, SC, Brazil
}

\section{A R T I C L E I N F O}

\section{Article history:}

Received 19 August 2015

Received in revised form

31 October 2015

Accepted 3 November 2015

Available online 24 December 2015

\section{Keywords:}

Ehrlichia canis

Iron

Transferrin

Ferritin

Oxidants

\begin{abstract}
A B S T R A C T
The aim of this study was to evaluate the oxidant profile and iron metabolism in serum of dogs infected by Ehrlichia canis. Banked sera samples of dogs were divided into two groups: negative control $(n=17)$ and infected by $E$. canis on acute $(n=24)$, and subclinical $(n=18)$ phases of the disease. The eritrogram, leucogram, and platelet counts were evaluate as well as iron, ferritin, and transferrin levels, latent iron binding capacity (LIBC), and transferrin saturation index (TSI) concentration. In addition, the advanced oxidation protein products (AOPP) and ferric reducing ability of plasma (FRAP) in sera were also analyzed. Blood samples were examined for the presence of E. canis by PCR techniques. History and clinical signals were recorded for each dog. During the acute phase of the disease, infected animals showed thrombocytopenia and anemia when compared to healthy animals $(P<0.05)$ as a consequence of lower iron levels. Ferritin and transferrin levels were higher in both phases (acute and subclinical) of the disease. The AOPP and FRAP levels increased in infected animals on the acute phase; however, the opposite occurred in the subclinical phase. We concluded that dogs naturally infected by $E$. canis showed changes in the iron metabolism and developed an oxidant status in consequence of disease pathophysiology.
\end{abstract}

() 2015 Elsevier Ltd. All rights reserved.

\section{Introduction}

Canine monocytotropic ehrlichiosis (CME) is an important disease with a worldwide distribution. Although CME has been considered specie-specific, studies have shown that this obligate intracellular gram-negative bacterium Ehrlichia canis transmitted by ticks Rhipicephalus sanguineus [1,2], may also infect other species

\footnotetext{
* Corresponding author. Department of Animal Science, Santa Catarina State University (UDESC), Chapecó, SC, Brazil. Tel.:+55 4933309432.

** Corresponding author. Department of Veterinary Clinic and Surgery, São Paulo State University (UNESP), Jaboticabal, Brazil.

E-mail addresses: crivellenti_lz@yahoo.com.br (L.Z. Crivellenti), dasilva. aleksandro@gmail.com (A.S. Da Silva).
}

besides dogs, including man [3].

CME is considered an endemic disease in Southeastern Brazil, showing acute, subclinical, and chronic phases, which are classified according to clinical signs and clinic-pathological abnormalities $[3,4]$. The acute phase is easily recognizable due to its clinical manifestation that includes: fever, weight loss, anorexia, bleeding disorders, lymphadenomegaly, anemia thrombocytopenia, and leucopenia [5-8]. On the other hand, the subclinical phase shows significant variable length, extending from months to years [9].

Traditional diagnostic techniques (hematology, cytology, serology, and isolation) are considered valuable tools for CME diagnosis. However, the immune response and the oxidant profile of dogs with CME infection also seem to play a central role in disease pathogenesis, especially when it is observed different clinical 
signs and/or laboratory and pathological findings [7,10].

Previous studies demonstrated that early endosomes containing different species of Ehrlichia (morulae) upregulate and accumulate the mammalian transferrin receptor [11], suggesting that Ehrlichia spp. has developed strategies for its own iron (Fe) acquisition. Besides other functions, Fe is directly involved with electron transport (cytochromes) and oxygen activation (oxidase and oxygenases), and transportation (hemoglobin and myoglobin) [12], and it is, consequently, important in the mechanism of anemia development. By presenting this information, the aim of this study was to evaluate the hematological parameters, iron metabolism, and oxidative profile in serum samples from dogs naturally infected by E. canis.

\section{Materials and methods}

\subsection{Animals}

Sera samples were collected from dogs naturally infected by E. canis; twenty four (24) on the acute phase of the disease (with clear clinical signs) and eighteen (18) with subclinical disease (asymptomatic). As a control group, sera samples from seventeen (17) healthy dogs were used.

Animal history, clinical signs, complete blood count (CBC), and biochemical profile were analyzed and recorded for each dog. Blood samples from all dogs were tested for the presence of $E$. canis, Babesia canis, Babesia gibsoni, and Anaplasma plattys by nested PCR [13-15].

\subsection{Hemogram}

Blood was collected and stored in tubes with EDTA for CBC. Blood samples were evaluated using an automated blood cell counter (ABC Vet. Horiba ABX - São Paulo, Brazil) to determine red blood cell (RBC) count, hemoglobin concentration (Hb), total leukocytes and platelets counts. Hematocrit was assessed by using the standard microhematocrit method (Centimicro mod. 1-15-Sigma, Germany). Blood smears were also prepared and stained for microscopic examination.

\subsection{Iron metabolism}

Iron (Fe) metabolism was assessed through the evaluation of the following variables: serum iron and latent iron-binding capacity (LIBC), through commercial kits (Labtest, Minas Gerais, Brazil) on a semi-automatic analyzer Bio-2000 (Bio Plus Ltda, São Paulo, Brazil). All glassware used was previously soaked into 10\% hydrochloric acid for $3 \mathrm{~h}$ and rinsed with deionized water (Milli-Q system from Millipore Corporation). Transferrin and ferritin concentrations were assessed using an automated immunoturbidimetry (Labtest, Minas Gerais, Brazil). Additionally, it was estimated the transferrin saturation index (TSI).

\subsection{AOPP and FRAP levels}

Protein oxidation status was evaluated through the measurement of AOPP concentrations as described by Hanasand et al. [16]. Levels of ferric reducing antioxidant power (FRAP) was measured according to the technique described by Benzie and Strain [17] in sera samples. AOPP and FRAP results were expressed as $\mu \mathrm{mol} \mathrm{L}{ }^{-1}$ according to the modified Griess method using the Cobas Mira automated analyzer.

\subsection{Statistical analysis}

Firstly, the data were subjected to normality test, where we verified a normal distribution. Then, the data were subjected to Tukey test. Values with probability (p) less than $5 \%$ were considered statistically different. Data were presented as mean values \pm standard deviation.

\section{Results}

\subsection{Clinical signs and hematological parameters}

As expected, control group and subclinically E. canis infected animals did not show clinical signs of the disease. However, dogs with $E$. canis acute infection showed several clinical signs, such as: apathy, appetite loss and intermittent fever. It is important to emphasize that more than $40 \%$ of the dogs with acute infection were also parasitized by ticks. Serology was negative for $B$. canis, $B$. gibsoni and A. plattys.

Peripheral blood smears showed hematological changes in animals infected by E. canis (Table 1). According to our results, it was possible to observe that animals with the acute phase the CME had a significant decrease $(P<0.05)$ in erythrocyte, hematocrit, hemoglobin and platelet counts when compared to healthy animals. For erythrocyte, hematocrit, hemoglobin and platelet parameters, no significant differences were observed on E. canis infected animals with the subclinical disease compared to healthy animals.

Leukocyte, lymphocyte, neutrophil, eosinophil and monocyte counts did not differ during the acute or subclinical phases of the disease when compared to healthy animals. In addition, the bands number, during the acute phase of disease, were higher in infected animals on the acute phase when compared to infected animals on the subclinical phase of CME and to healthy animals.

\subsection{Iron metabolism}

Iron, ferritin, transferrin, LIBC, and TSI levels are shown in Table 2. E. canis infected animals showed a significant increase of ferritin, transferrin, and TSI levels during the acute phase of CME, when compared with healthy animals. Additionally, Fe level significantly decreased during the acute phase of CME compared to healthy animals. Also, ferritin and transferrin levels increased on animals on subclinical disease in comparison to the control group $(\mathrm{P}<0.05)$. There were no differences on Fe and TSI levels on infected animals with the subclinical phase of CME. Furthermore, LIBC serum levels did not differ on E. canis infected animals.

Ferritin, transferrin and TSI levels were lower in infected animals during subclinical phase, when compared with animals on the acute phase. However, Fe levels were higher in infected animals on subclinical phase than in infected animals on the acute phase of disease.

\subsection{AOPP and FRAP levels}

AOPP and FRAP results are shown in Table 2. Animals on acute CME presented increased levels of AOPP and FRAP on sera when compared to healthy animals. Similarly, FRAP levels increased in dogs on the subclinical phase when compared to the control group $(\mathrm{P}<0.05)$. There were no differences on AOPP levels in infected animals on the subclinical phase of CME. AOPP and FRAP levels were significantly lower in infected animals on the subclinical disease, when compared to dogs on the acute phase of disease. 
Table 1

Eritrogram, leucogram and platelet counts in dogs naturally infected by Ehrlichia canis: acute and subclinical disease compared to healthy animals.

\begin{tabular}{|c|c|c|c|}
\hline Variables & Healthy dogs control & Infected dogs acute phase & Infected dogs chronic phase \\
\hline Total erythrocytes $\left(\times 10^{6} / \mu \mathrm{L}\right)$ & $5.85 \pm 1.22^{\mathrm{a}}$ & $4.47 \pm 1.17^{b}$ & $5.64 \pm 1.50^{\mathrm{ab}}$ \\
\hline Hemoglobin $(\mathrm{g} / \mathrm{dL})$ & $13.4 \pm 2.4^{\mathrm{a}}$ & $9.72 \pm 2.8^{b}$ & $13.3 \pm 3.5^{\mathrm{ab}}$ \\
\hline Hematocrit (\%) & $40.1 \pm 7.4^{\mathrm{a}}$ & $28.4 \pm 7.4^{\mathrm{b}}$ & $38.7 \pm 10.1^{\mathrm{ab}}$ \\
\hline Total leukocytes $\left(\times 10^{3} / \mu \mathrm{L}\right)$ & $7.76 \pm 2.96^{\mathrm{a}}$ & $6.80 \pm 3.34^{\mathrm{a}}$ & $8.27 \pm 5.5^{\mathrm{a}}$ \\
\hline Lymphocytes $\left(\times 10^{3} / \mu \mathrm{L}\right)$ & $2.25 \pm 1.21^{\mathrm{a}}$ & $2.24 \pm 1.42^{\mathrm{a}}$ & $2.03 \pm 0.97^{\mathrm{a}}$ \\
\hline Neutrophils $\left(\times 10^{3} / \mu \mathrm{L}\right)$ & $4.38 \pm 1.88^{\mathrm{a}}$ & $3.69 \pm 2.31^{\mathrm{a}}$ & $5.41 \pm 2.96^{\mathrm{a}}$ \\
\hline Bands $(/ \mu \mathrm{L})$ & $45.8 \pm 72.2^{\mathrm{a}}$ & $199.5 \pm 89.61^{b}$ & $60.3 \pm 57.2^{\mathrm{a}}$ \\
\hline Eosinophils $(/ \mu \mathrm{L})$ & $615.4 \pm 534.2^{\mathrm{a}}$ & $214.4 \pm 229.1^{\mathrm{a}}$ & $377.1 \pm 298.2^{\mathrm{a}}$ \\
\hline Monocytes $(/ \mu \mathrm{L})$ & $465.6 \pm 420.1^{\mathrm{a}}$ & $455.6 \pm 256.4^{\mathrm{a}}$ & $391.1 \pm 420.2^{\mathrm{a}}$ \\
\hline Platelets $\left(\times 10^{3} / \mu \mathrm{L}\right)$ & $294.4 \pm 111.4^{\mathrm{a}}$ & $90.2 \pm 64.2^{\mathrm{b}}$ & $228.3 \pm 140.0^{\mathrm{a}}$ \\
\hline
\end{tabular}

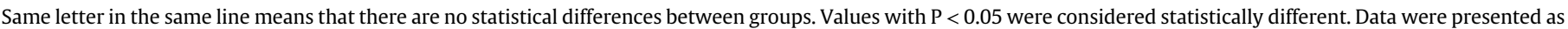
mean values \pm standard deviation.

Table 2

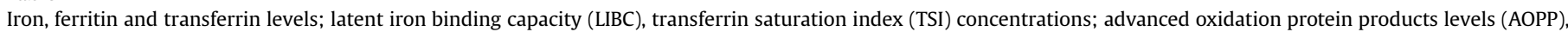
and ferric reducing antioxidant power (FRAP) of dogs naturally infected by Ehrlichia canis (acute and chronic phases) compared to healthy dogs (control).

\begin{tabular}{|c|c|c|c|}
\hline Variable & Healthy dogs control & Infected dogs acute phase & Infected dogs subclinical phase \\
\hline $\operatorname{Iron}\left(\mu \mathrm{g} \mathrm{dL}^{-1}\right)$ & $106.31 \pm 7.8^{\mathrm{a}}$ & $78.6 \pm 5.9^{b}$ & $99.5 \pm 6.8^{\mathrm{a}}$ \\
\hline Ferritin $\left(\mathrm{ng} \mathrm{mL}^{-1}\right)$ & $1.25 \pm 0.26^{\mathrm{a}}$ & $8.74 \pm 1.58^{\mathrm{b}}$ & $3.34 \pm 1.41^{\mathrm{c}}$ \\
\hline Transferrin (mg dL $\left.{ }^{-1}\right)$ & $213.6 \pm 11.2^{\mathrm{a}}$ & $412.2 \pm 31.4^{\mathrm{b}}$ & $286.4 \pm 19.1^{c}$ \\
\hline $\operatorname{LIBC}\left(\mu \mathrm{g} \mathrm{dL}^{-1}\right)$ & $302.1 \pm 21.6^{\mathrm{a}}$ & $289.7 \pm 37.1^{\mathrm{a}}$ & $321.4 \pm 48.1^{\mathrm{a}}$ \\
\hline TSI $(\%)$ & $37.8 \pm 4.1^{\mathrm{a}}$ & $49.6 \pm 7.2^{\mathrm{b}}$ & $41.4 \pm 3.1^{\mathrm{a}}$ \\
\hline AOPP $\left(\mu \mathrm{mol} \mathrm{L}^{-1}\right)$ & $39.0 \pm 3.8^{\mathrm{a}}$ & $56.7 \pm 6.1^{\mathrm{b}}$ & $43.7 \pm 4.6^{\mathrm{a}}$ \\
\hline $\operatorname{FRAP}\left(\mu \mathrm{mol} \mathrm{L}^{-1}\right)$ & $189.1 \pm 48.5^{\mathrm{a}}$ & $535.1 \pm 96.8^{b}$ & $379.4 \pm 52.4^{c}$ \\
\hline
\end{tabular}

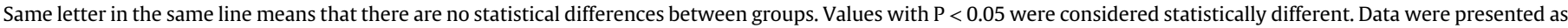
mean values \pm standard deviation.

\section{Discussion}

This study focused on profiling the oxidative mechanisms and the iron metabolism in sera samples from dogs naturally infected by E. canis. Following the normal pattern of CME, infected dogs showed clinical signs such as inappetence, hyperthermia and apathy, as previously described by Munhoz et al. [18]. In order to validate our study data, E. canis infection in dogs was confirmed by PCR.

Dogs presenting clinical signs of the infection showed more pronounced laboratorial abnormalities than dogs under subclinical stage. In agreement with these results, some authors consider that alterations in globulin levels can be related to the length of infection [19]. We observed some hematological changes in infected animals on the acute phase, especially anemia and thrombocytopenia. Anemia is a frequent finding in ehrlichiosis [20], similarly to other canine blood diseases such as leishmaniasis, hepatozoonosis and babesiosis [21-23]. In these situations, usually Fe concentration is also reduced. We believe that infected animals in the acute phase of CME, and with number of E. canis in infected dogs was high, these developed anemia as result of Fe metabolism. Doyle et al. [24] observed an Fbp $38 \mathrm{kDa}$ protein in E. canis, which is involved in the acquisition and transportation of iron. Our results suggest that $E$. canis uses Fe available in the serum in order to maintain its survival, reducing Fe levels in infected animals during the acute phase. This is just a hypothesis, however the mechanism of decrease serum iron levels are not well known in ehrlichiosis, but it is related to high bacteremia, iron therapy in acute infection shouldn't be recommended. Ehrlichia upregulates the transferrin receptor and recruits it to the intracytoplasmic vacuole (morula) [24]. It corroborates our findings, since the importance of Fe for intracellular survival and proliferation of Ehrlichia have already been demonstrated [11]. Low circulating Fe levels induces the expression of iron binding proteins, such as the extracellular transferrin for Fe transport into tissues, whereas the intracellular ferritin sequestrates Fe. The Fe deficiency may exacerbate the anemia in the myelosuppressive phase of the disease, interfering in the hematopoietic process [20].

Low Fe levels in sera of animals infected by $E$. canis during the acute phase of the disease, associated with high transferrin and normal LIBC levels indicate a higher production of hepatic transferrin, presumably attempting to maximize the use of lower extracellular iron. During subclinical stages, infected animals develop an anemia, similarly to the anemia observed on chronic disease. In these cases, there are normal Fe levels in sera, but the majority of this $\mathrm{Fe}$ is associated with ferritin and transferrin, keeping the LIBC and TSI presumably normal, and allowing the resistance mechanism against $E$. canis, especially through upregulating the levels of hepcidin, a hormone produced in liver that regulates Fe homeostasis [25]. Hepcidin is released during the inflammatory process mediated by IL-6, an important cytokine in the immune response against $E$. canis [26]. IL-6 promotes the release of hepcidin in turns, leading to the decrease of seric Fe [25], which causes changes in the immune response, since lymphoid cells are dependent on Fe for cell division, electron transport, oxidation-reduction reactions, and phagocytic activity [25,27].

Regarding the mechanism of thrombocytopenia, it may involve immune destruction (mainly during the acute phase) by increasing platelet consumption, decreasing platelet half-life, splenic sequestration or, it may be secondary to increased concentrations of circulating platelet migration-inhibition factor [28,29]. The thrombocytopenia is the hallmark of acute stage and it is usually characterizing by the presence of megaplatelets in the peripheral blood [28]. Our results showed exactly this pattern, since thrombocytopenia was found in dogs under acute infection, but not on those with the chronic form of the disease or healthy. There is also the hypothesis that antiplatelet antibodies also act on bone marrow megakarocytes with deleterious effects on thrombopoiesis [30], collaborating with the process of platelets depletion in dogs acutely affected by E. canis.

It is possible to correlate our hematological results to oxidative damage to red blood cells, a process related to the generation of free 
radicals [31]. Our data show increased levels of AOPP and FRAP, both variables in sera of infected animals with $E$. canis during the acute phase. These are antagonistic biomarkers, since increased levels of AOPP indicates the enhancement of protein oxidation [32], while FRAP measures the total antioxidant capacity (TAC) [17]. Enhanced oxidative stress reduces erythrocyte deformability [33,34], contributing to hemolysis, and to the development of anemia [35]. It was already reported that AOPP has direct relation with anemia in malaria [36]. Furthermore, E. canis plays an oxidative stress through lipoperoxidation [37] contributing to high levels of AOPP. Thus, due to the increase of AOPP levels observed during the acute phase of $\mathrm{CME}$ in our study, it is possible to assume that there was a biologic response provided by FRAP increase, as an attempt to provide a balance between oxidant and anti-oxidant mechanisms. Additionally, these results indicate a direct effect on NO levels, since Fe plays an inhibitory role on the expression of inducible NO synthase (iNOS). There were no differences on AOPP levels between control group and animals on subclinical phase of CME, indicating reduction on hematological damage. However, FRAP levels still increased in animals under acute and subclinical phase, when compared to the control group. Therefore, even without protein oxidation in subclinical animals, the total antioxidant capacity still increased when compared to the control group, indicating a long-term antioxidant activity. Also, reduction AOPP and FRAP levels, on subclinical phase of CME show a restoration of serum iron.

Positive results from PCR for E. canis validated our model and reinforced our results. The main changes observed were found during the acute phase of the disease. During this phase, it was observed that $E$. canis infection lead to anemia and thrombocytopenia, and we correlated this anemia mainly to iron metabolism. Added to these hematological alterations, we observed increased FRAP and AOPP levels. Therefore, our results indicated hematological and oxidative imbalance, especially during the acute phase of ehrlichiosis.

\section{Commission of ethics and animal welfare}

The present study was approved by the Ethics Committee for Use of Animals (CEUA) of São Paulo State University (UNESP), Jaboticabal Campus, under protocol number 010290/14.

\section{References}

[1] M.G. Groves, G.L. Dennis, H.L. Amyx, D.L. Huxsoll, Transmission of Ehrlichia canis to dogs by ticks (Rhipicephalus sanguineus), Am. J. Vet. Res. 36 (1975) 937-940.

[2] C. Bulla, R.K. Takahira, J.P. Araújo, L.A. Trinca, R.S. Lopes, C.E. Wiedmeyer, The relationship between the degree of thrombocytopenia and infection with Ehrlichia canis in an endemic area, Vet. Res. 35 (2004) 141-146.

[3] R.F.C. Vieira, T.S.W.J. Vieira, D.A.G. Nascimento, T.F. Martins, F.S. Krawczak M.B. Labruna, et al., Serological survey of Ehrlichia species in dogs, horses and humans: zoonotic scenery in a rural settlement from southern Brazil, Rev. Inst. Med. Trop. 55 (2013).

[4] T. Waner, G Baneth, C. Strenger, A. Keysary, R. King S. Harrus, Antibodies reactive with Ehrlichia canis, Ehrlichia phagocytophila genogroup antigens and the spotted fever group rickettsial antigens, in free-ranging jackals (Canis aureus syriacus) from Israel, Vet. Parasitol. 82 (1999) 121-128.

[5] T.M. Neer, S. Harrus, Canine monocytotropic ehrlichiosis and neorickettsiosis (E. canis, E. chaffeensis, E. ruminantium, N. sennetsu, and N. risticii infections), in: C.E. Greene (Ed.), Infectious Diseases of the Dog and Cat, Saunders Elsevier, St. Louis, 2006, pp. 203-216.

[6] S. Harrus, T. Waner, Y. Avidar, E. Bogin, H.C. Peh, H. Bark, Serum protein alterations in canine ehrlichiosis, Vet. Parasitol. 66 (1997) 241-249.

[7] S. Harrus, T. Waner, Diagnosis of canine monocytotropic ehrlichiosis (Ehrlichia canis). An overview, Vet. J. 187 (2011) 292-296.

[8] L.A. Sangione, Rickéttsias, in: S.G. Monteiro (Ed.), Parasitologia Na Medicina Veterinária, 17, Roca, São Paulo, 2011, pp. 169-179.

[9] T. Waner, S. Harrus, H. Bark, E. Bogin, Y. Avidar, A. Keysary, Characterization of the subclinical phase of canine ehrlichiosis in experimentally infected beagle dogs, Vet. Parasitol. 69 (1997) 307-317.

[10] A.S. Da Silva, T.D. Munhoz, J.L.M. Faria, G. Vargas-Hérnandez, R.Z. Machado,
T.C. Almeida, et al., Increase nitric oxide and oxidative stress in dogs experimentally infected by Ehrlichia canis: effect on the pathogenesis of the disease, Vet. Microbiol. 164 (2013a) 366-369.

[11] R.E. Barnewall, Y. Rikihisa, E.H. Lee, Ehrlichia chaffeensis inclusions are early endosomes which selectively accumulate transferrin receptor, Infect. Immun. 65 (1997) 1455-1461.

[12] D.M. Williams, D. Loukopoulos, G.R. Lee, G.E. Cartwright, Role of copper in mitochondrial iron metabolism, Blood 48 (1976) 77-85.

[13] H. Inokuma, K. Fujii, M. Okuda, T. Onishi, J.P. Beaufils, D. Raoult, et al., Determination of the nucleotide sequences of heat shock operon groesl and the citrate synthase gene (gltA) of Anaplasma (Ehrlichia) platys for phylogenetic and diagnostic studies, Clin. Diag. Lab. Immun. 9 (2002) 1132-1136.

[14] C. Bulla, R.K. Takahira, J.P. Araújo, L.A. Trinca, R.S. Lopes, C.E. Wiedmeyer, The relationship between the degree of thrombocytopenia and infection with Ehrlichia canis in an endemic area, Vet. Res. 34 (2003) 1-6.

[15] A.J. Birkenheuer, M.G. Levy, E.B. Breitschwerdt, Development and evaluation of a seminested PCR for detection and differentiation of Babesia gibsoni (Asian genotype) and B. canis DNA in canine blood samples, J. Clin. Microbiol. 41 (2003) 4172-4177.

[16] M. Hanasand, R. Omdal, K.B. Norheim, L.G. Goransson, C. Brede, Improved detection of advanced oxidation protein products in plasma, Clin. Chim. Acta 413 (2012) 901-906

[17] I.F.F. Benzie, J.J. Strain, The ferric reducing ability of plasma (FRAP) as a measure of "antioxidant power": the FRAP assay, Anal. Biochem. 239 (1996) 70-76.

[18] T.D. Munhoz, J.L.M. Faria, G. Vargas-Hérnandez, J.J. Fagliari, A.E. Santana, R.Z. Machado, M. Tinucci-Costa, Experimental Ehrlichia canis infection changes acute-phase proteins, Rev. Bras. Parasitol. Vet. 21 (2012) 206-212.

[19] B.J. Woody, J.D. Hoskins, Ehrlichial diseases in dogs, Vet. Clin. North. Am. (Small Anim. Pract. 21 (1991) 75-98.

[20] M.E. Mylonaki, M.J. Day, V. Siarkou, W. Vernau, A.F. Koutinas, Absence of myelofibrosis in dogs with myelosuppression induced by Ehrlichia canis infection, J. Comp. Pathol. 142 (2010) 328-331.

[21] S. Pasa, F. Kargin, A. Bildik, K. Seyrek, Y. Ozbel, S. Ozensoy, Serum and hair levels of zinc and other elements in dogs with visceral leishmaniasis, Biol. Trace Elem. Res. 94 (2003) 141-147.

[22] S. Chaudhuri, J.P. Varshney, R.C. Patra, Erythrocytic antioxidant defense, lipid peroxides level and blood iron, zinc and copper concentrations in dogs naturally infected with Babesia gibsoni, Res. Vet. Sci. 85 (2008) 120-124.

[23] K. Seyrek, T. Karagenc, S. Pasa, F. Kiral, A. Atasoy, Serum zinc, iron and copper concentrations in dogs infected with Hepatozoon canis, Acta Vet. Brno 78 (2009) 471-475.

[24] C.K. Doyle, X. Zhang, V.L. Popov, J.W. McBride, An immunoreactive 38-kilodalton protein of Ehrlichia canis shares structural homology and iron-binding capacity with the ferric ion-binding protein family, Infect. Immun. 73 (2005) $62-69$

[25] H.Z.W. Grotto, Metabolismo do ferro: uma revisão sobre os principais mecanismos envolvidos em sua homeostase, Rev. Hematol. Hemoter. 30 (2008) $390-397$.

[26] A. Unver, H. Huang, Y. Rikihisa, Cytokine gene expression by peripheral blood leukocytes in dogs experimentally infected with a new virulent strain of Ehrlichia canis, Ann. N.Y. Acad. Sci. 1078 (2006) 482-486.

[27] K.E. Saker, Nutrition and immune function, Vet. Clin. North Am. Small Anim. Pract. 36 (2006) 1199-1224

[28] T. Waner, S. Harms, D.J. Weiss, H. Bark, A. Keysary, Demonstration of serum antiplatelet antibodies in experimental acute canine ehrlichiosis, Vet. Immunol. Immunopathol. 48 (1995) 177-182.

[29] S. Harrus, T. Waner, H. Bark, F. Jongejan, A.W. Cornelissen, Recent advances in determining the pathogenesis of canine monocytic ehrlichiosis, J. Clin. Microbiol. 37 (1998) 2745-2749.

[30] J.L. Lachowicz, G.S. Post, S.D. Moroff, S.C. Mooney, Acquired amegakaryocytic thrombocytopenia-four cases and a literature review, J. Small. Anim. Prac. 45 (2004) 507-514.

[31] J.L. Vives-Corrons, A. Miguel-Garcia, M.A. Pujades, A. Miguel-Sosa, S. Cambiazzo, M. Linares, Increased susceptibility of microcytic red blood cells to in vitro oxidative stress, Eur. J. Haematol. 55 (1995) 327-331.

[32] V. Witko-Sarsat, M. Friedlander, C. Capeillere-Blandin, T. Nguyen-Khoa, A.T. Nguyen, J. Zingraff, P. Jungers, B. Descamps-Latscha, Advanced oxidation protein products as a novel marker of oxidative stress in uremia, Kidney Int. 49 (1996) 1304-1313.

[33] O.K. Baskurt, A. Temiz, H.J. Meiselman, Effect of superoxide anions on red blood cell rheologic properties, Free Radic. Biol. Med. 24 (1998) 102-110.

[34] A. Skorokhod, E. Schwarzer, G. Gremo, P. Arese, HNE produced by the malaria parasite Plasmodium falciparum generates HNE-protein adducts and decreases erythrocyte deformability, Redox Rep. 12 (2007) 73-75.

[35] K. Becker, L. Tilley, J.L. Vennerstrom, D. Roberts, S. Rogerson, H. Ginsburg, Oxidative stress in malaria parasite-infected erythrocytes: host-parasite interactions, Int. J. Parasitol. 34 (2004) 163-189.

[36] G. Zhang, O.A. Skorokhod, S.K. Khoo, R. Aguilar, S. Wiertsema, A.J. Nhabomba, T. Marrocco, et al., Plasma advanced oxidative protein products are associated with anti oxidative stress pathway genes and malaria in a longitudinal cohort, Malar. J. 13 (2014) 134.

[37] A.S. Da Silva, T.D. Munhoz, J.M. Faria, G. Vargas-Hérnandez, R.Z. Machado, N.C. Luz, et al., Influence of experimental canine ehrlichiosis on the E-ADA activity and purine levels in serum and possible functional correlations with pathogenesis, Vet. Microbiol. 166 (2013b) 602-606. 